\title{
Enhanced tolerance to water stress in adults of the South India strain of the seed beetle, Callosobruchus maculatus (Coleoptera: Bruchidae), as a product of large body size
}

\author{
JAY A. YODER ${ }^{1}$, BRADY S. CHRISTENSEN ${ }^{1}$ and GEORge D. KEENEY ${ }^{2}$ \\ ${ }^{1}$ Department of Biology, Wittenberg University, Springfield, OH 45501, USA; e-mail: jyoder@wittenberg.edu \\ ${ }^{2}$ Department of Entomology, The Ohio State University, Columbus, OH 43210, USA
}

Key words. Water balance, net transpiration rate, activation energy, Callosobruchus

\begin{abstract}
A water balance study was conducted on newly-emerged adults of seed beetle, Callosobruchus maculatus, to explore how South India strain survives longer than Brazil strain in laboratory cultures. No difference between strains was noted with regard to dehydration tolerance, and water conservation features confirm classification of this species as xerophilic. There was no evidence for critical transition temperature (CTT), thereby safeguarding against excessive water loss as the temperature rises, or for critical equilibrium humidity $(\mathrm{CEH})$, indicating that water is imbibed as a liquid. In contrast to the Brazil strain, adults of the South India strain were distinguished by a larger body size, resulting in a lower net transpiration rate with suppressed activation energy $\left(E_{\mathrm{a}}\right.$, permeability constant) for water loss, and a lower percentage body water content due to a higher dry mass (fat). These modifications for water balance of the South India strain link enhancing time for reproduction and distribution spread in the adult with the higher seed consumption/respiratory rate trait that has been previously reported for larvae of this strain.
\end{abstract}

\section{INTRODUCTION}

Larval competition behavior is one of the most distinctive features of the seed beetle Callosobruchus maculatus, which is one of the most widespread and serious pests of stored legumes throughout the world (Southgate, 1979). Development of this beetle occurs inside a single bean host, with adult females laying eggs on the bean surface. The larvae hatch, burrow straight down to the seed without exposing itself, and feed within the seed, creating a transparent window through the seed coat, which makes the beetle visible. They pupate, and then adults exit the seed by way of the window. Upon emergence from the seed, adults mate, oviposition occurs and death typically occurs within a week requiring no food or water (Mitchell, 1975). Thus, these beetles feed only as larvae, allowing for the outcome of competition to be evaluated in the adult. The South India strain has a contest (attack) behavioral process of larval competition and a contest outcome where one, or few, adults emerge per seed. Brazil strain of this same species has a scramble process of competition where several to only one adult emerges per single seed (Smith \& Lessels, 1985; Guedes et al., 2003). Because how these beetles are reared is reminiscent of the storage facilities that they inhabit (dry, air-tight containers at room temperature and low relative humidity), laboratory observations likely reflect what occurs in nature (Messina \& Mitchell, 1989).

In our laboratory colonies, we have observed that adults of the South India (contest) strain are typically much longer lived than adults from the Brazil (scramble) strain. The capacity to function properly in the environment depends upon the ability to maintain adequate levels of body water (Hadley, 1994). It has been shown for adults of $C$. maculatus that this species is xerophilic (Appel et al., 1999), conducive for thriving in hot, dry storage bins. In this study we compare adult females and males from the South India and Brazil strains to determine moisture requirements that are fundamental for survival, and to explore whether this difference in longevity may be due to a particular water balance characteristic (i.e., percentage body water content, net transpiration rate, dehydration tolerance, activation energy) that may be exploited for control purposes. Because of the ability to function regularly as adults illustrated by successful mating and oviposition without having to drink free water or obtain moisture from food, our study also seeks to examine whether these beetles can absorb water vapor from the air (i.e., critical equilibrium humidity) as a potential water resource.

\section{MATERIAL AND METHODS}

\section{Seed beetles, test conditions and instrumentation}

Callosobruchus maculatus were obtained from laboratory colonies that have been maintained at The Ohio State University for many years (Messina \& Mitchell, 1989; Mitchell, 1975). Rearing conditions were $25^{\circ} \mathrm{C}, 12 \mathrm{~L}: 12 \mathrm{D}$ photoperiod, and $70 \%$ R.H. We used sedentary morphs rather than the active dispersal morph, because the sedentary morph is the predominant form under storage conditions and laboratory colonies and causes the most economic damage. An aspirator was used to handle beetles.

Brazil and South India strains were raised on the type of bean (purchased in Columbus, $\mathrm{OH}$ ) on which they were collected. The strain from South India originated from Tirunelveli, India in 1979 and was reared on mung bean, Vigna radiata L. The strain from Brazil originated from Campinas, Brazil in 1975 and was reared on cowpea, Vigna unguiculata (L.). Females have stripes on the pygidium and are black, whereas males lack stripes and are brown with a smaller pygidium (Bandara \& Saxena, 1995). To rule out differences due to diet, both strains were reared on cowpea for two generations (Guedes et al., 2003). After emergence of the second generation, beetles were stored individually in $1.5 \mathrm{cc}$ mesh-covered chambers for $48 \mathrm{~h}$, as adults do not require food or liquid water (Mitchell, 1975).

Temperature for basic observations was $25^{\circ} \mathrm{C}$, which allows for the most comparison with water balance literature (Hadley, 
TABLE 1. Water balance profile for adults of Callosobruchus maculatus. $f$ - fresh (initial) mass; $d$-dry mass; $m$ - water mass; $\%$ - percentage body water content; NTR - net transpiration rate $(\% / \mathrm{h})$; DT - dehydration tolerance $(\%)$; $E_{\mathrm{a}}-$ activation energy $(\mathrm{kJ} / \mathrm{mol})$; CTT - critical transition temperature; drinking - evidence of blue tracer in gut; CEH - critical equilibrium humidity; -, not detected; + , detected. Survival is for $50 \%$ of beetles in absence of food and water. Data are mean \pm SE ( 20 beetles per replicate, $\mathrm{n}=3)$.

\begin{tabular}{|c|c|c|c|c|}
\hline \multirow{3}{*}{ Characteristics } & \multicolumn{4}{|c|}{ Beetle strain } \\
\hline & \multicolumn{2}{|c|}{ Brazil (scramble) } & \multicolumn{2}{|c|}{ South India (contest) } \\
\hline & Female & Male & Female & Male \\
\hline \multicolumn{5}{|l|}{ Water content } \\
\hline$f(\mathrm{mg})$ & $2.89+0.27$ & $2.11+0.18$ & $5.07+0.25$ & $3.40+0.21$ \\
\hline$d(\mathrm{mg})$ & $1.29+0.15$ & $0.91+0.06$ & $2.47+0.08$ & $1.65+0.09$ \\
\hline$m(\mathrm{mg})$ & $1.60+0.22$ & $1.20+0.20$ & $2.59+0.16$ & $1.75+0.14$ \\
\hline$m / d$ & 1.24 & 1.32 & 1.05 & 1.07 \\
\hline$\%$ & $55.26+2.3$ & $56.87+2.7$ & $51.20+1.6$ & $51.58+1.8$ \\
\hline \multicolumn{5}{|l|}{ Water loss } \\
\hline NTR & $0.48+0.04$ & $0.67+0.07$ & $0.31+0.03$ & $0.44+0.04$ \\
\hline DT & $21.6+1.6$ & $19.3+2.1$ & $17.9+1.5$ & $22.4+1.7$ \\
\hline$E_{a}$ & 34.3 & 39.6 & 20.8 & 25.2 \\
\hline CTT $\left({ }^{\circ} \mathrm{C}\right)$ & - & - & - & - \\
\hline \multicolumn{5}{|l|}{ Water gain } \\
\hline drinking & + & + & + & + \\
\hline CEH $(\%$ RH $)$ & $>99$ & $>99$ & $>99$ & $>99$ \\
\hline Survival (days) at $0 \% \mathrm{RH}$ & $4.7+0.5$ & $2.1+0.8$ & $10.5+1.1$ & $4.2+0.8$ \\
\hline
\end{tabular}

$1994)$ and is within the temperature that prevails $\left(21-34^{\circ} \mathrm{C}\right)$ in Tirunelveli, with storage bins being $22-30^{\circ} \mathrm{C}$. This is also within ambient conditions, $22-24^{\circ} \mathrm{C}$, which is customary for the Brazil strain (Messina \& Mitchell, 1989). Temperature was controlled within environmental cabinets $\left( \pm 1^{\circ} \mathrm{C}\right)$ and relative humidity was controlled within sealed $3000 \mathrm{cc}(\mathrm{L} \times \mathrm{W} \times \mathrm{H})$ glass desiccators ( $\pm 1 \%$ R.H.) and was measured with a hygrometer $( \pm 0.5 \%$ R.H., Thomas Scientific, Philadelphia, PA). Test relative humidities (still air conditions) were generated using saturated salt solutions and glycerol-distilled water mixtures (Johnson, 1940; Winston \& Bates, 1960). Selection of relative humidities for testing was based upon previous water balance studies, $100 \%$ R.H. (deionized, double-distilled water), 98\% R.H., 93\% R.H., 85\% R.H., 75\% R.H. and 0\% R.H. (anhydrous $\mathrm{CaSO}_{4}$, Toolson, 1978) as outlined by Wharton (1985).

Beetles were removed from their $1.5 \mathrm{cc}$ mesh-covered chamber for mass measurements and behavioral observations, taking $<1$ min before they were returned to their enclosure and experimental conditions. No anesthesia was used. Weighing was accomplished using an electrobalance $( \pm 0.2 \mu \mathrm{g}$ precision and \pm $6 \mu \mathrm{g}$ accuracy at $1 \mathrm{mg}$; Cahn, Ventron Co., Cerritos, CA). Before experimentation, beetles were held at $0 \%$ R.H. until 4-6\% body mass had been lost, a typical pre-treatment that standardizes specimens so that changes in mass reflect changes in the beetle's body water (Benoit et al., 2005). A $90^{\circ} \mathrm{C}$ drying oven containing $\mathrm{CaSO}_{4}$ was used to dry the beetles to constant mass for determination of dry mass $(d)$ at the end of each experiment (Wharton, 1985; Hadley, 1994).

\section{Determination of water balance characteristics}

By standard convention (Wharton, 1985), $f$ is fresh (initial) mass, $d$ is dry mass and the difference is the amount of water available for exchange, known as water mass, $m$. Dry mass was subtracted from mass measurements to convert mass measurements to water mass $(m)$ values. Percentage body water content was expressed as a percentage of initial (fresh) mass: percentage $m=100(f-d) / f$. Dehydration tolerance was defined as the percentage change in mass corresponding to the mass measurement $\left(m_{\mathrm{C}}\right.$, critical water mass) where beetles were observed having their legs curled, exhibited irregular ambulatory activity, uncoordinated movement and failed to crawl ten body lengths when prodded; percentage change in $m=100\left(m_{\mathrm{C}}-m_{0}\right) / m_{0}$, where $m_{0}$ is the initial water mass (Benoit et al., 2005). Corresponding survival estimates were made for $50 \%$ of beetles. Dead beetles were those that were immobile and unresponsive to prodding when examined by a $40 \times$ light microscope.

Net transpiration rate (NTR, integumental plus respiratory water loss) was determined at $0 \%$ R.H., $25^{\circ} \mathrm{C}$, with daily mass measurements, because under $0 \%$ R.H. conditions water loss is exponential as described $m_{t}=m_{0} \mathrm{e}^{-k t}$, where $m_{t}$ is the water mass at any time $t$ and $-k_{t}$ is the rate of water loss permitting the net transpiration rate to be derived from the slope of a regression. Activation energy $\left(E_{\mathrm{a}}\right)$ for water loss, as an indicator of cuticular permeability (Wharton, 1985), was derived similarly except beetles were first killed (freeze/thaw or $\mathrm{HCN}$ ) to eliminate respiratory artifacts. Temperature was varied, basing the calculation on the Arrhenius equation, $k=A \mathrm{e}^{(-E a / R T)}$, where $k$ is rate of water loss (determined at $0 \%$ R.H. to permit derivation of the rate from the slope of an exponential regression), $A$ is frequency (steric) factor, $R$ is gas constant and $T$ is absolute temperature. The activation energy is determined from the slope $\left(-E_{\mathrm{a}} / R\right)$ of a regression through the Arrhenius plot. A change in activation energy denotes the temperature where water loss accelerates sharply due to a phase change in cuticular lipids, known as the critical transition temperature (CTT) as described by Gibbs (2002).

Critical equilibrium humidity ( $\mathrm{CEH}$, lowest relative humidity where water vapor absorption occurs) was based upon $48 \mathrm{~h}$ weighing intervals for beetles exposed to $75 \%$ R.H., $85 \%$ R.H., 93\% R.H., 98\% R.H. and 100\% R.H. until they died (Wharton, 1985). Capacity for water vapor absorption is based upon $0.99 a_{\mathrm{w}}$ body water activity and that in absence of an active mechanism for water vapor uptake to occur, any relative humidity below a water vapor activity of $0.99 a_{\mathrm{v}}\left(a_{\mathrm{v}}=\%\right.$ R.H./100) results in net water loss by diffusion; hence, $0.99 a_{\mathrm{w}}>0.93 a_{\mathrm{v}}$ (Wharton, 1985). Net water gain occurs at $1.00 a_{\mathrm{v}}$ because the activity gradient is reversed. Maintenance of water mass $(\mathrm{m})$ in dynamic equilibrium in subsaturated air indicates that water gain is balancing water loss by diffusion and is evidence of water vapor 
A)

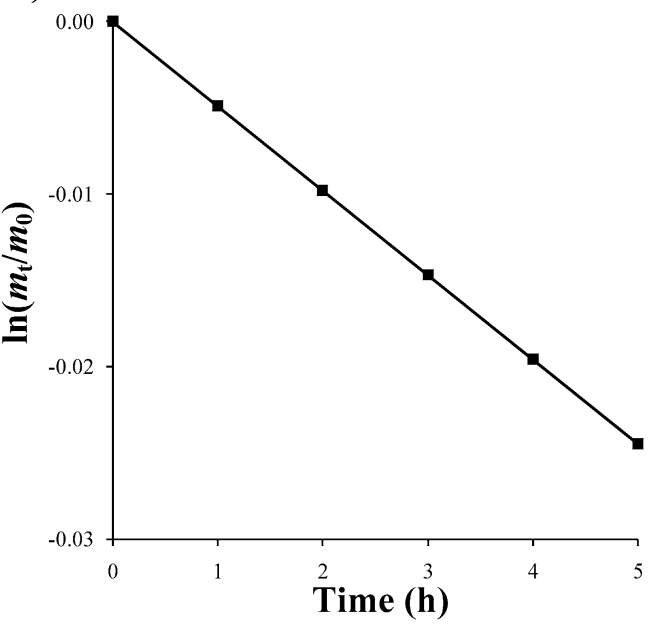

C)

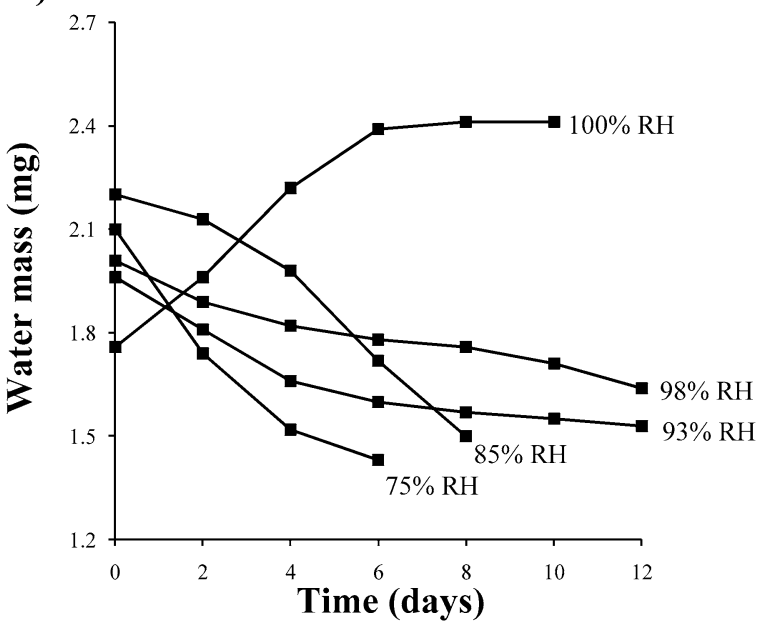

B)

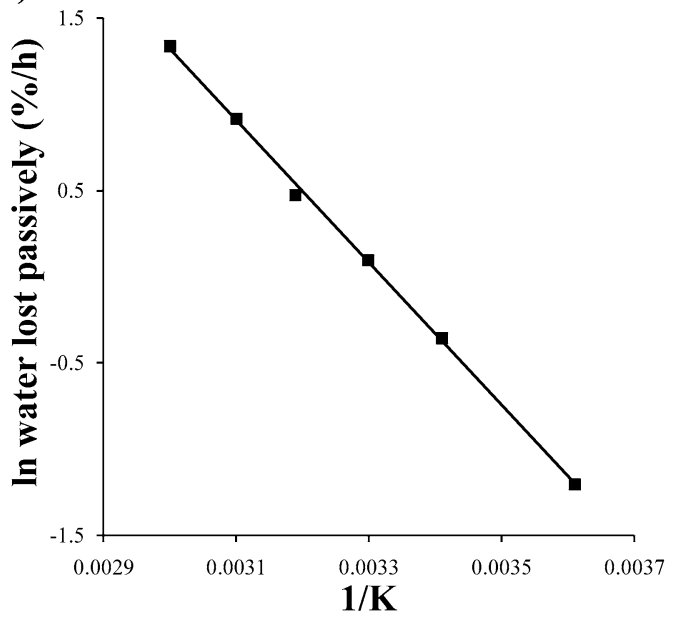

Fig. 1. Representative plots for female adults of the Brazil strain of Callosobruchus maculatus for determination of (A) net transpiration rate $\left(m_{t}-\right.$ water mass at any time $t ; m_{0}$ - initial water mass); (B) activation energy for water loss (HCN-killed beetles yielded similar results) and (C) critical equilibrium humidity. Each point is the mean $\pm \mathrm{SE}$ of 60 individuals and error bars lie within confines of symbols used on the graph.

absorption (Wharton, 1985). To test for the ability to drink liquid water, ten beetles were exposed to ten $20 \mu 1$ droplets of $0.1 \%$ Evans blue stained water in a $100 \times 15 \mathrm{~mm}$ petri dish for $24 \mathrm{~h}$, using a $20 \times$ hand lens for behavioral observations followed by dissection in $1.0 \% \mathrm{NaCl}$ (prior water rinse to remove residual dye) to examine for incorporation of the blue tracer (Benoit et al., 2005).

\section{Sample sizes and statistics}

Each experiment was replicated three times using 20 beetles per replicate or until 60 beetles were tested. The same group of 60 beetles was not used for all determinations, and each replicate represents beetles from a different rearing batch. Data are mean \pm SE and were compared using a two-way analysis of variance (ANOVA), following an arcsin transformation in the case of percentages. Data used for activation energy and critical equilibrium humidity determination were analyzed by analysis of covariance (ANCOVA) with temperature and time as covariates to test strain differences following a test for the equality of slopes of several regressions (Sokal \& Rohlf, 1995).

\section{RESULTS}

\section{Water balance profile for adults of Brazil strain}

Percentage body water content for female adults was 55.3\%, water mass correlated positively with dry mass $(\mathrm{r}=0.91, \mathrm{p}<$ $0.001)$, water mass to dry mass $(\mathrm{m} / \mathrm{d})$ ratio was 1.24 , and they were similar in size, shape and body water content (Table 1). Under $0 \%$ R.H. and $25^{\circ} \mathrm{C}$ conditions, female adults were able to survive 4.7 days without food and water, and this agrees with their ability to sustain an approximate $22 \%$ body water loss before succumbing to desiccation stress factoring in a loss (net transpiration rate, NTR) of $0.48 \%$ body water/hour (Fig. 1A, Table 1). They did not experience a change in activation energy averaging $34 \mathrm{~kJ} / \mathrm{mol}$, as evidenced by a continuous slope of a regular Boltzmann temperature function of evaporative water loss rates $(r=0.99, p<0.001$, Fig. 1B). Thus, no critical transition temperature (CTT) is apparent denoting an abrupt water loss increase. As anticipated, water loss rate was 2-3 times higher for killed rather than living specimens when compared at $25^{\circ} \mathrm{C}$ (Fig. 1A and B), demonstrating the importance of life processes in controlling respiratory water loss. Except at saturation, water mass declined at all test relative humidities (Fig. 
1C), and gains were passive as indicated by increased water retention as air became more humid $(\mathrm{r}=0.89, \mathrm{p}<0.001)$. Thus, they cannot absorb water vapor from subsaturated air; i.e., critical equilibrium humidity $(\mathrm{CEH})>99 \%$ R.H. Drinking from water droplets was noted (observation of blue tracer filling the gut and detection of coloration upon dissection), but the beetles did not appear to be attracted to the droplets (no deliberate movement toward droplets); rather, encounters with the droplets were passive, pausing only to drink on occasion.

Water mass to dry mass correlation for males was $r=0.93(p$ $<0.001$ ), and ratio of water mass to dry mass between sexes was similar, averaging 1.28 (Table 1). Except for a higher net transpiration rate, related to the male's smaller body size, and associated higher activation energy, all remaining water balance characteristics between males and females were alike. Higher net transpiration rate of males translated into corresponding survival time of 2.1 days without food and water, corroborating an approximate $20 \%$ dehydration tolerance limit. In contrast, length of survival for females was about 5 days $(\mathrm{p}<0.05)$. We concluded that females are larger in body size and more resistant to desiccation stress by retaining water more effectively than males.

\section{Comparative observations with adults from South India strain}

Females were larger than males $(p<0.05)$, and they had similar percentage body water content and water mass to dry mass ratios ( $p>0.05$; Table 1$)$. Neither sex experienced a CTT or had the ability to absorb water vapor from the air (CEH > $99 \%$ R.H.), and although they were not attracted to the droplets they were capable of drinking liquid water (Table 1). For both sexes, water mass was a positive correlate of dry mass $(r=0.92$ for females, $\mathrm{r}=0.94$ for males, $\mathrm{p}<0.001$ ), and within a sex, beetles were similar in body size, shape and water content. Net transpiration rates and activation energies of males were higher than females and correlated with two-fold longer survival time without food and water for females. Given that both succumb to desiccation once about $20 \%$ water has been lost as verification of our technique, survival time was 10.5 days for females compared to 4.2 days for males $(\mathrm{p}<0.05)$. Thus, greater length of survival associated with low net transpiration rate of females is attributed to larger size compared to the males.

When compared to the Brazil strain, females and males of the South India strain were nearly two-times larger in body size, had smaller water mass to dry mass ratio and a lower percentage body water content (Table $1, \mathrm{p}<0.05$ ). Comparing sexes of strains (Table 1) shows survival times in dry air and in the absence of food were approximately two times longer for the South India strain than the Brazil strain $(\mathrm{p}<0.05)$ in correlation with slower net transpiration rates and associated lower activation energies. The strains were alike in that they drank from water droplets, displayed no particular attraction to the droplets, failed to absorb water vapor from the air (CEH $>99 \%$ R.H.), exhibited a tolerance for about $20 \%$ loss before succumbing to desiccation, and displayed no evidence of a CTT (Table 1). Our conclusion is that adults of the South India strain are larger in body size, but not water content, and lose water more slowly than adults of the Brazil strain contributing to greater survival capacity.

\section{DISCUSSION}

Adults of C. maculatus are like most beetles that have been studied in that the presence of a thicker, heavily sclerotized cuticle has the effect of producing: (1) low percentage body water content that is $10-15 \%<68 \%$ mean water content of majority of arthropods; (2) slow net transpiration rate, averaging
$<1 \% / \mathrm{h}$, indicative of a water-impermeable barrier despite large surface area to volume ratio; and (3) suppressed activation energy for water loss ranging 20-70 $\mathrm{kJ} / \mathrm{mol}$, representing the presence of a cuticular modification that is restrictive to water movement (Hadley, 1994; Yoder et al., 1999; Benoit et al., 2005). Most beetles are seemingly protected against dehydration by lack of CTT (Benoit et al., 2005), suggesting that the cuticle retains its watertight properties at high temperature (Gibbs, 2002), and this is especially useful for survival in hot habitats (Benoit et al., 2005). Absence of CTT in these beetles necessarily implies that cuticular lipids do not undergo a reorganization to become less fluid (more watertight) as the temperature drops such that the activation energy changes. Adults of $C$. maculatus are also characterized by requiring no water as liquid (Mitchell, 1975) or vapor (this study; CEH > 99\% R.H.). From a water balance perspective, the ability by adult $C$. maculatus to retain water is more important than their ability to gain water, and this agrees with a xerophilic water balance classification as defined by Hadley (1994) where the emphasis is on water conservation.

The results of this water balance profile analysis also conforms to Appel et al.'s (1999) ecological classification of $C$. maculatus as xerophilic and matches the hot, dry conditions of storage facilities and arid to semi-arid biotopes where this beetle thrives (Southgate, 1979). Similar values and adjustments to these characteristics in the water balance profile of this species resemble those of desert-inhabiting arthropods (Hadley, 1994). Most arthropods can handle $20-30 \%$ losses of body water before succumbing to desiccation stress (Hadley, 1994). Dehydration tolerance limit in Brazil and South India strains of $C$. maculatus adults is at the lower end of this range, as is that of the highly sensitive Carabus beetles (Schmidt, 1955). Thus, $C$. maculatus is xeric-suited and is modified for water conservation but not desiccation-hardiness.

A higher respiratory rate as larvae is one of the features of the South India strain compared to the Brazil strain. In fact, these respiratory rates of the larva represent the extremes with South India being the highest and Brazil the lowest when larvae of other strains of C. maculatus are compared (Guedes et al., 2003). Increased seed consumption necessitates increased rates of respiration and leads to larger emerging adults for the South India strain (Guedes et al., 2003). Indeed, we demonstrate in this study by fresh mass values that are nearly twice as large for adults of South India than their Brazil strain counterparts. The larger body size translates into lower net transpiration rate for adults of South India through surface area to volume properties. The lower net transpiration rate is also reflected by lower activation energies for water loss that reveal that these beetles experience less passive water loss jumping from one temperature to the next by Arrhenius analysis, as an indirect measure of effective water retention by decreasing integumental water loss and displays the restrictive properties of the heavily sclerotized beetle's cuticular armor. Evidence of heightened feeding activity in South India strain larvae is also reflected by higher dry mass values in the adult, as an indicator of body fat (Hadley, 1994), which has the effect of lowering percentage body water content and lowering the water mass to dry mass ratio. These connections to larval feeding can be made because seed beetle adults feed only as larvae in the experiment, and this is not related to food quality because larvae were fed on the same cowpea host.

From this study it is clear that adults of the South India strain feature prolonged survivorship when compared to the Brazil strain, and this is a direct outcome of altering specific water balance characteristics due to a difference in body size. The difference in tolerance to water stress is attributed to the larger body size of the South India strain that results in a lower net transpira- 
tion rate with reduced activation energy for water loss and a lower percentage body water content. Although speculative, the different water balance profiles likely arises because larvae of the South India strain feed more leading to larger adults as reported by Guedes et al. (2003).

\section{REFERENCES}

Appael A.G., Moar W.J. \& Tanley M.J. 1999: Water loss and mortality of adult cowpea weevils (Coleoptera: Bruchidae) exposed to desiccants and desiccating environments. Environ. Entomol. 28: 979-982.

Bandara K.A.N.P. \& Saxena R.C. 1995: A technique for handling and sexing Callosobruchus maculatus (F.) adults (Coleoptera: Bruchidae). J. Stored Prod. Res. 31: 97-100.

Benoit J.B., Yoder J.A., Rellinger E.J., Ark J.T. \& Keeney G.D. 2005: Prolonged maintenance of water balance by adult females of the American spider beetle, Mezium affine Boieldieu, in the absence of food and water resources. $J$. Insect Physiol. 51: 565-573.

GibBs A.G. 2002: Lipid melting and cuticular permeability: New insights into an old problem. J. Insect Physiol. 48: 391-400.

Guedes R.N.C., Smith R.H. \& Guedes N.M.P. 2003: Host suitability, respiration rate and the outcome of larval competition in strains of the cowpea weevil, Callosobruchus maculatus. Physiol. Entomol. 28: 298-305.

HadLey N.F. 1994: Water Relations of Terrestrial Arthropods. Academic Press, New York, 356 pp.

JoHNSON C.G. 1940: The maintenance of high atmospheric humidities for entomological work with glycerol-water mixtures. Ann. Appl. Biol. 27: 295-299.

Messina F.J. \& Mitchell R. 1989: Intraspecific variation in the egg-spacing behavior of the seed beetle Callosobruchus maculatus. J. Insect Behav. 2: 727-742.
Mitchell R. 1975: The evolution of oviposition tactics in the bean weevil, Callosobruchus maculatus (F.). Ecology 56: 696-702.

Schmidt G. 1955: Physiologische Untersuchungen zur Transpiration and zum Wassergehalt der Gattung Carabus (Ins. Coleopt.). Zool. Jb. Anat. 65: 459-495.

Smith R.H. \& Lessells C.M. 1985: Oviposition, ovicide and larval competition in granivorous insects. In Sibly R.M. \& Smith R.H. (eds): Behavioral Ecology: Ecological Consequences of Adaptative Behaviour. Blackwell, London, pp. 423-448.

SoKal R.R. \& Rohlf F.J. 1995: Biometry: The Principles and Practice of Statistics in Biological Research. 3. Freeman, San Francisco, 887 pp.

Southgate B.J. 1979: Biology of the Bruchidae. Annu. Rev. Entomol. 24: 449-473.

Toolson E.C. 1978: Diffusion of water through the arthropod cuticle: Thermodynamic consideration of the transition phenomenon. J. Therm. Biol. 3: 69-73.

Wharton G.W. 1985: Water balance of insects. In Kerkut G.A. \& Gilbert L.I. (eds): Comprehensive Insect Physiology, Biochemistry, and Pharmacology. 4. Pergamon Press, Oxford, pp. 565-603.

Winston P.W. \& Bates D.S. 1960: Saturated solutions for the control of humidity in biological research. Ecology 41: 232-237.

Yoder J.A., Houck M.A., Goodin B.R. \& SMith J.A. 1999: Maintenance of water balance in the twice-stabbed ladybird beetle, Chilocorus cacti (Coleoptera: Coccinellidae), despite heavy infestation by the mite, Hemisarcoptes cooremani (Acari: Acariformes). Int. J. Acarol. 25: 337-340.

Received December 10, 2009; revised and accepted January 19, 2010 